\title{
Study of Guangxi's Green Innovation Efficiency of High-tech Industries Based on Data Envelopment Analysis
}

\author{
Feng WEI \\ School of Management: Science and technology department, \\ Guangxi University of Science and Technology \\ Liuzhou, China \\ Bo-ming FENG \\ School of Management: Science and technology department, \\ Guangxi University of Science and Technology \\ Liuzhou, China \\ 416512806@qq.com
}

\author{
Pei-pei WU \\ School of Management: Science and technology department, \\ Guangxi University of Science and Technology \\ Liuzhou, China \\ Yong-yi QING \\ School of Management: Science and technology department, \\ Guangxi University of Science and Technology \\ Liuzhou, China
}

\begin{abstract}
In order to optimize the structure of high-tech industries in Guangxi and improve the economic, social and environmental benefits of Guangxi's high-tech industries, this paper innovatively measured and compared the green innovation efficiency of Guangxi high-tech industries in the past eleven years from the perspective of vertical. These results find that the average efficiency of green innovation in high-tech industries in Guangxi is high in the past eleven years, but the staff investment and capital investment are redundant in the past two years. In order to improve the green innovation efficiency of high-tech industries, and to promote the sustainable development of hightech industry in Guangxi, it is suggested to increase the cluster construction of green innovation industry, build a green innovation technology knowledge and information exchange and sharing platform, the production process and technology for green transformation, establish payment for ecosystem service.
\end{abstract}

Keywords-Green Innovation Efficiency; Guangxi; High-tech Industries; Data Envelopment Analysis

\section{INTRODUCTION}

In recent years, with the deterioration of the environment and the growing shortage of resources, people attach importance to the ecological environment. Low-carbon Economy, Sustainable Development, Green Development and other related research continue to rise. In the report of the work of the Eighteenth National Congress of the Communist Party of China, Ecological civilization has written a five-in-one construction process. The Eighth Plenary Session of the 18th Central Committee pointed out that it is necessary to firmly establish and implement the concept of innovation, coordination, green, openness and sharing in the development of the "13th Five-Year Plan" period, to solve the development problems and to develop the advantages. You can find the government's emphasis on green and innovation. At the same time, People's awareness of green consumption has been strengthened, the production of enterprises to pay the environmental costs continues to rise, which requires enterprises to carry out the direction of green innovation. Therefore, as a high-tech industries represented by advanced technology, its green innovation is more demanding and more urgent. How to more effectively improve the efficiency of high-tech industries' green innovation, promote the transformation of high-tech industries development, and create more energy-saving environmental protection of high-tech products and technology, is the next period of time need to work in the direction.

According to statistics, during 2015, the main business income of high-tech industries in Guangxi is 1791 billion yuan, which ranked 19th in China, and the total profit of 16.9 billion Yuan, which ranked 16th in China. Contrast from the provinces and autonomous regions, the development of high-tech industries in Guangxi is the middle level. This paper use DEA method to evaluate Green Enovation Efficiency of high-tech industries in Guangxi to find the current high-tech industries in Guangxi green innovation problems and structure of the irrational. Through the structure and direction of adjustment, investment in capital optimization and other means to improve the efficiency of green technology innovation in Guangxi hightech industries to accelerate the transformation of high-tech industries in Guangxi, and even in the domestic and other international competition in the same industries to develop a unique competition Advantages, to achieve the sustainable development of high-tech industries in Guangxi.

\section{LITERATURE REVIEW}

Green innovation is often referred to as ecological innovation, environmental innovation, and sustainable innovation. The Organization for Economic Co-operation and Development (2008) defines green innovation as an enterprise without a total environmental innovation, specifically for enterprises through their products, processes, organizational structures and institutional arrangements for new or significant improvements, etc. Peer better environment improvement ${ }^{[1]}$. 
Rennings et al. (2016) argue that green innovation refers to innovations in the form of new processes, technologies, practices, systems and products that are ultimately beneficial to environmental benefits and sustainable development in order to avoid or reduce environmental pollution ${ }^{[2]}$.

Domestic and foreign scholars have made a lot of research on the efficiency of green innovation. Most of the scholars use DEA method or other methods to improve the efficiency of green innovation. Li Jinyan et al. (2016) used the SBM-DEA model with the expected output and the Global MalmquistLuenberger index to study the efficiency of urban green innovation $^{[3]}$.Yao Xilong (2015) uses DEA-RAM model to construct a model of industrial economy transformation efficiency including environmental efficiency, economic efficiency and innovation efficiency. According to this model, the green innovation efficiency of China's overall and different provinces can be measured ${ }^{[4]}$. Niu Tong (2015) used the improved SBM-DEA four-stage method to evaluate the green innovation efficiency of industrial enterprises in 29 provinces (autonomous regions and municipalities) from 2006 to $2012^{[5]}$. Ren Yao(2014) based on the DEA-RAM model to construct a green innovation efficiency model that embodies the green development and innovation-driven concept, which is a link efficiency model that includes green efficiency, innovation efficiency and economic efficiency ${ }^{[6]}$.Some scholars have used other methods to measure the efficiency of green innovation. Such as Feng Zhijun (2013) through the factor analysis of China's regional green innovation efficiency measurement ${ }^{[7]}$. Cao Xia et al. (2015) from the green lowcarbon perspective through the use of projection pursuit model, stochastic frontier analysis model of China's regional innovation efficiency and impact factors empirical analysis ${ }^{[8]}$.Wang Yong et al. (2016) used Super-SBM model to measure the green innovation efficiency of China's high-tech industries under the constraint of environment and construct the threshold model to analyze the influence of R \& D input intensity on $\mathrm{it}^{[9]}$.

There are scholars on the efficiency of high-tech industries related research, Li Xiaomei (2013) on the 2003-2009 China's high-tech industries economic efficiency of the empirical study ${ }^{[10]}$.Xiao Renqiao et al. (2012) conducted an empirical analysis on the innovation efficiency of high-tech industries in 28 provinces in China from 2005 to $2009^{[11]}$.Zhang Hua(2012) measured the technology innovation efficiency of high-tech industries in Tianjin ${ }^{[12]}$.Wu Weihong(2014) evaluates the efficiency of technological innovation in Beijing's high-tech industries and puts forward suggestions for optimizing the investment structure of science and technology funds, raising the utilization rate of science and technology funds and increasing the number of patent licenses ${ }^{[13]}$. Based on the nonradial and non-angle SBM model, Wang Chuanyu(2016) measured and compared the green innovation efficiency of China's inter-provincial high-tech industries without considering the undesirable output and considering the undesirable output. Durbin model analysis of regional hightech industries green innovation efficiency of the spatial spillover effect ${ }^{[14]}$.The above studies take into account the impact of environmental factors on the innovation efficiency of high-tech industries, and rarely analyze the changes in green innovation efficiency in the region from a vertical perspective. Therefore, this paper uses DEA method to measure the green innovation efficiency of high-tech industries in Guangxi, and puts forward relevant suggestions and measures for green innovation efficiency in combination with the present situation of green innovation and innovation of high-tech industries in Guangxi, hoping to promote the sustainable development of high-tech industries in Guangxi.

\section{EMPIRICAL ANALYSIS}

After extensive reference to the results of the predecessors, the study selected high-tech industries R\&D staff full-time equivalent, $R \& D$ internal expenses, high-tech industries energy consumption (unified conversion of standard coal) as input variable indicators. This paper Selected high-tech industries sales of new products, high-tech industries, the number of patent applications, high-tech industries environmental pollution index (by the high-tech industries, wastewater emissions, waste gas emissions and solid waste emissions formed a comprehensive indicator) as output indicators. Through the access to "China Science and Technology Yearbook", "Guangxi Statistical Yearbook" to collect relevant data. Use DEAP 2.1 software to measure the green innovation efficiency of Guangxi high - tech industry from 2006 to 2015.The results are shown in Table 1:

TABLE I. EVALUATION TABLE OF GREEN INNOVATION EFFICIENCY OF HIGH-TECH INDUSTRIES FROM

\begin{tabular}{|c|c|c|c|c|}
\hline year & crste & vrste & scale & scale pay \\
\hline 2015 & 0.846 & 0.846 & 0.999 & irs \\
\hline 2014 & 0.844 & 0.845 & 0.999 & irs \\
\hline 2013 & 1 & 1 & 1 & crs \\
\hline 2012 & 0.828 & 0.835 & 0.992 & drs \\
\hline 2011 & 0.704 & 0.707 & 0.995 & irs \\
\hline 2010 & 1 & 1 & 1 & crs \\
\hline 2009 & 0.933 & 0.938 & 0.995 & drs \\
\hline 2008 & 1 & 1 & 1 & crs \\
\hline 2007 & 1 & 1 & 1 & crs \\
\hline 2006 & 0.81 & 0.948 & 0.854 & irs \\
\hline 2005 & 1 & 1 & 1 & crs \\
\hline mean & 0.91 & 0.92 & 0.98 & - \\
\hline
\end{tabular}

From Table 1 can be found, Guangxi high-tech industries green innovation efficiency to achieve the best are year 2005, 2007, 2008, 2010 and 2013.11 years of comprehensive efficiency, pure technical efficiency and scale efficiency of the mean more than 0.9 , so that nearly 11 years of high-tech industries in Guangxi green innovation efficiency is higher. This is because the Guangxi government in recent years to increase the construction and guidance of high-tech industries, the implementation of innovation-driven strategy, innovation as the first driving force to develop Guangxi, aimed at economic and social development needs and major scientific and technological needs, adhere to scientific and technological 
innovation Core to enhance regional innovation capacity, adhere to the industrial transformation and upgrading as the goal to promote economic quality and efficiency, adhere to market demand-oriented to promote scientific and technological achievements to speed up the transformation. It is of great significance to improve the efficiency of green innovation in Guangxi high-tech industry. The key is to improve the efficiency of pure technology. By strengthening the system innovation and technological innovation, it is necessary to improve the efficiency of green innovation in Guangxi's high-tech industry. And management innovation, improve the high-tech industry resource utilization and technology conversion rate, on the other hand, optimize the high-tech industry input-output structure, research and development projects for the researchers to streamline and appropriate to reduce $\mathrm{R} \& \mathrm{D}$ funding, while increasing green product revenue And the number of patent applications, is conducive to improving the efficiency of green innovation in Guangxi high-tech industry. For example, the green innovation efficiency in 2015 is not optimal, and DE9 data are found to be redundant, so $5.1 \% \mathrm{R} \& \mathrm{D}$ researchers and $8.5 \% \mathrm{R} \& \mathrm{D}$ research spending should be reduced, with a $5 \%$ increase in new product revenue And $9 \%$ of the number of patent applications can make green innovation efficiency to achieve the best. In the case of reduced investment need to increase the output, the need to improve the researchers' ability to innovate and transform the results, while enterprises and governments need to build a good platform for innovation and entrepreneurship, information sharing platform and the combination of production and research results conversion platform.

\section{SUGGESTIONS ON IMPROVING THE EFFICIENCY OF GREEN INNOVATION OF HIGH-TECH INDUSTRIES IN GUANGXI}

\section{A. Increase the green innovation industry cluster construction}

Industrial cluster is a must for the development of a mature industry. Through the establishment of high-tech enterprises such as green innovation and industrialization parks or bases, it can promote the exchange of green innovation knowledge, technology, resources and information among enterprises, so that the resources are maximized The use of green information between enterprises and technology to get more extensive exchanges and collisions, more conducive to the development of green products and technology and innovation. The government should play a leading role in guiding and promoting the cooperation between the enterprises in the ecology of the cluster through the use of a mixed investment approach to promote innovation and cooperation between enterprises. The government can invest in part of the capital or land to take the lead in building eco-innovation cooperation platform, followed by the government can continue to introduce some preferential policies to encourage the development of green cooperation between clusters of innovative platform, such as the construction of green ecocreative cooperative industrial park, the government of this enterprise Green cooperation between the green policy to facilitate the policy and some subsidies and incentives.

\section{B. Build Green Creative Technology Knowledge and Information Exchange Platform}

As the main body of green innovation, high-tech industry enterprises themselves should actively build a green innovation technology, knowledge and information exchange platform, open and cooperative development of industrial platform, the development of ecological strategy to promote business and supply chain upstream and downstream enterprises As well as with the school and related scientific research units, so that the "production and research" three aspects of the organic combination of continuous commitment to green manufacturing, intensive development and low-carbon development of three aspects of improvement and research innovation, and further promote the product to the ecological, The development of intensive and intensive aspects.

\section{The production process and technology for green transformation}

With the continuous improvement of green standards, hightech industry enterprises need to re-product from the perspective of the life cycle of green design and improvement, from product design, procurement of raw materials to the product manufacturing process, packaging and transportation process, sales Process and the final product recycling process are pay attention to green. At the same time, the use of intensive development ideas, through technological progress and improve management, in the use of human resources continue to improve labor productivity in the use of material resources continue to reduce the level of material consumption in the use of financial resources continue to improve investment returns and capital use effects, And ultimately achieve the purpose of improving the reduction of production costs, improve the total factor productivity, increase the economic efficiency of enterprises, social and environmental benefits.

\section{Establish payment for ecosystem service}

Ecological compensation mechanism is to protect the ecological environment, promote harmony between man and nature for the purpose, according to the ecosystem service value, ecological protection costs, and the opportunity to develop opportunities, the comprehensive use of administrative and market means to adjust the ecological environment protection and construction of the interests of the parties a system of relations. The implementation of ecological compensation mechanism in Guangxi is conducive to the participation of all parties involved in environmental protection and ecological construction, fostering the resource market, opening up the factor of production market, capitalizing the resources and ecological capitalization, so that the price of environmental factors really reflect their scarcity Saving resources and reduce the dual effects of pollution, and actively explore the use of resources, emissions trading and other market-oriented compensation model. Improve the rational allocation of water resources and paid use of the system to speed up the establishment of water resources to take the right to transfer, transfer and lease trading mechanism. To explore the establishment of regional pollutant emission index paid distribution mechanism, the gradual implementation of 
government regulation under the emissions trading, the use of market mechanisms to reduce pollution control costs and improve pollution control efficiency. Guide to encourage ecoenvironmental protection and beneficiaries through voluntary consultation to achieve a reasonable ecological compensation.

\section{CONCLUSION}

Through the empirical study of this paper, the following conclusions are drawn:

A. From 2005 to 2015, Guangxi high-tech industries, green innovation efficiency comparison can be found, the current high-tech industries in Guangxi green innovation efficiency level is higher, the utilization of resources is better, but still need to adjust the relevant investment Out of the structure to make green innovation efficiency to achieve better.

B. From the green innovation efficiency in 2014 and 2015, it can be found that the scale of the high-tech industries in Guangxi is increasing in scale, and there is a redundant situation in the staff investment and capital investment. Therefore, it is necessary to reduce the investment in these two aspects, Income and the number of patent applications, which requires high-tech industries to increase their technology into products and income capacity, through a series of technological innovation, institutional innovation and management innovation to improve its conversion efficiency.

C. In order to improve the green innovation efficiency of high-tech industry in Guangxi, it is proposed to increase the cluster construction of green innovation industry, build green innovation technology knowledge and information exchange and sharing platform, greenize the production process and process, and establish payment for ecosystem service.

\section{ACKNOWLEDGMENT}

This research was financially supported by National Social Science Foundation of China(15BJY077),Liuzhou Federation of Social Science Circles(liushekelian[2016]18),Liuzhou Social Science Research Institute Philosophy and Social Sciences Research Project(SKL-04),Innovation Project of Guangxi University of Science and Technology Graduation Education (GKYC201614).

\section{REFERENCES}

[1] Li Jinyan,Li Zheyu,Li Zhao. An Empirical Study on Green Efficiency of Urban Green-Evidence from urban agglomerations in the middle reaches of the Yangtze Rive[J].Journal of Jiangxi University of Finance and Economics,2016,(06):3-16.(In Chinese)

[2] Yao Xilong,Niu Chonghuai, Liu Jia. Innovation Driven, Green Growth and Industrial Economic Efficiency[J].China Science and Technology Forum,2015,(01):57-62.(In Chinese)

[3] Niu Tong,Peng Shuyuan,Niu Chonghuai, Chen Xinguo, Du Biyun. Study of Shanxi's Green Innovation Efficiency of Industrial Enterprises Based on SBM Model and Four-stage DEA Approach[J].Science and Technology Management Research,2015,(10):244-249.(In Chinese)

[4] Ren Yao,Niu Chonghuai, Niu tong, Yao Xilong. Theoretical Model and Empirical Study on Green Innovation Efficiency[J].Management World,2014,(07):176-177.(In Chinese)

[5] Feng Zhijun. Research on Green Innovation Efficiency of Chinese Industrial Enterprises[J].China Science and Technology Forum,2013,(02):82-88(In Chinese)

[6] Cao Xia,Yu Juan. Regional Innovation Efficiency in China from the Green Low-carbon Perspective[J].China Population, Resources and Environment,2015,(05):10-19.(In Chinese)

[7] Wang Hui,Wang Shuqiao,Miao Zhuang,Li Xiaocong. Heterogeneity threshold effect of R\&D investment on green innovation efficiency based on Chinese high-tech industries[J].Science Research Management,2016,37(02):63-71.(In Chinese)

[8] Li Xiaomei.Research on Economic Efficiency of High-tech Industries in China based on DEA[J].Technoeconomics \& Management Research,2013,(2):120-124.(In Chinese)

[9] Xiao Renqiao,Qian Li,Chen Zhongwei. Research on the Innovation Efficiency and Its Affecting Factors in China's High-tech Industries,Journal of Management Science,2012,(10):85-98.(In Chinese)

[10] Zhang Hua.Tianjin High-tech Industrial Technology Innovation Efficiency Evaluation[D].Tianjin: Tianjin University of Commerce,2012.(In Chinese)

[11] Wu Weihong,Wang Yangyang,Zhang Aimei. Evaluation on the Technological Innovation Efficiency of High-tech Industries in Beijing[J].Journal of Yunnan University of Finance and Economics,2014,(02):133-139.(In Chinese)

[12] Wang Chuanxu,Ren Yangjun. Research on Spatial Spillover Effect of the Green Innovation Efficiency of High-tech Industries[J].Forward Position or Economics,2016,(06):76-84.(In Chinese)

[13] Wu Weihong,Wang Yangyang,Zhang Aimei. Evaluation on the Technological Innovation Efficiency of High-tech Industries in Beijing[J].Journal of Yunnan University of Finance and Economics,2014,(02):133-139.(In Chinese)

[14] Wang Chuanxu,Ren Yangjun. Research on Spatial Spillover Effect of the Green Innovation Efficiency of High-tech Industries[J].Forward Position or Economics,2016,(06):76-84.(In Chinese) 